RESENHAS DE TrRADUÇÃO/ TRANSLATIONS REVIEWS 


\title{
MOLIÈRE. O Misantropo. Tradução de Bárbara Heliodora. Rio de Janeiro: Zahar, 2014. 126 p.
}

\author{
Fernângela Diniz Silva* \\ Universidade Federal do Ceará
}

Ícone teatral no século XVII, Jean Baptiste Poquelin eternizou seu nome nas artes como Molière, adotando esse pseudônimo por volta de 1644 , momento que abandona a tapeçaria do pai e opta por viver do teatro. A mudança do nome de batismo deve-se, sobretudo, ao fato de não querer expor o nome de sua família, uma vez que eram muitas as dificuldades vividas pelos artistas na época.

Nesse período, Molière funda, juntamente com os seus colegas, o grupo teatral Illustre Théâtre. No entanto, não obtém sucesso, amargando dívidas, o que resulta em sua prisão. Após o infortúnio, o dramaturgo, resiliente na sua vocação teatral, integra-se a um grupo itinerante, com o qual percorre algumas províncias francesas. Sua glória cênica aparece em 1659, graças ao sucesso de Les Précieuses ridicules, cuja temática revela o seu tempo, elaborando uma caricatura social do século XVII. Entre suas obras, Molière conta com peças polêmicas, a exemplo de L'école des femmes (1663), Tartuffe (1664), Dom Juan (1665) e Le Misanthrope

\footnotetext{
* Mestranda do programa de Pós-Graduação Letras, na área de Literatura Comparada, pela Universidade Federal do Ceará. Graduada em Letras Português/ Francês pela Universidade Federal do Ceará. Bolsista CAPES. Fortaleza, Ceará, Brasil. E-mail:fernangela_diniz@hotmail.com
} 
(1666), objeto da presente resenha. Mais adiante, foram encenadas as peças L'avare (1668), Le Bourgeois gentilhome (1670) e Le Malade imaginaire (1672).

Analisando seu percurso de dramaturgo, podemos concluir que Molière se afirma como um homem do teatro, isso porque além de dramaturgo e responsável por trupes teatrais, era também ator. Um dos personagens interpretados por Molière chama-se Alceste, protagonista de $O$ Misantropo, peça encenada pela primeira vez em Paris, no ano de 1666. Na época, não teve muita repercussão, sendo encenada poucas vezes ao ano; todavia, seu conteúdo crítico perdura até os dias atuais. Para a produção de $O$ Misantropo, Molière espelhou-se no clássico homônimo do grego Menandro; entretanto, Molière pinta com teor irônico sua narrativa, haja vista o exagero expresso na figura de Alceste, adaptando o enredo ao contexto histórico em que viveu.

Traduzido em 2014 pela ensaísta e crítica brasileira Bárbara Heliodora, $O$ Misantropo narra a história de Alceste, cujo comportamento é um desafio veemente a qualquer hipocrisia ou conveniência social pautada por bajulações. Contudo, Alceste é apaixonado por Célimène, moça cortejada por alguns rapazes, incluindo os marqueses Acaste e Clitandre. Alceste acaba enfrentando diversos problemas por conta de sua sinceridade sem limites, o que culmina em um processo executado por Oronte. No decorrer das ações, o leitor acompanha os embates entre Alceste e a sociedade da época.

O Misantropo é composto por cinco atos. O primeiro, dividido em três cenas, apresenta um diálogo entre Alceste e Philinte. Nesta cena, o protagonista condena a conduta de Philinte e o acusa de ser gentil com todos, inclusive com aqueles de caráter duvidoso, como afirma Alceste: "Odeio os homens todos, e ela é total.../Uns por serem desonestos, maus, e safados;/ Outros por complacência com os pecados" (MOLIÈRE, 2014, p. 20). Esse trecho explica bem o título, já que qualificamos de misantropo os indivíduos que 
possuem aversão aos seres humanos em geral. Alceste possui essa caraterística, ao enfatizar os defeitos de todas as pessoas, inclusive a de sua amada Célimène.

É também no primeiro ato que encontramos o episódio no qual Oronte, depois de muitos elogios, pede que Alceste ouça seus sonetos e os julgue. Alceste, agindo sem comedimento, não faz cerimônia e repudia a produção do personagem, ao contrário de Philinte que cobre Oronte de louvores.

O segundo ato, composto por cinco cenas, focará a conversa entre Alceste e Célimène. Aqui, Alceste repudia as amizades e o jeito de ser da moça: "Tem amantes demais, gosta deles cercar-se" (MOLIÈRE, 2014, p. 42). Logo depois, chegam outros personagens que interrompem a conversa, a exemplo do marquês Acaste e do marquês Clitandre, além de Éliante, prima de Célimène. A partir disso, a conversa toma um rumo que indigna o protagonista: "Os que riem, senhora, a aplaudem, enfim;/ E ainda mais se a sátira é contra mim" (MOLIĖRE, 2014, p. 57). Adiante, Alceste é convocado ao tribunal, devido ao desentendimento com Oronte.

Nas cinco cenas que compõem o ato três, assistimos os marqueses discorrendo sobre o amor de Célimène. Eles iniciam uma competição para saber quem, de fato, a parisiense ama. Podemos verificar a proposta nas palavras de Clitandre: "Se um de nós mostrar indício, com razão, / De Célimène ter conquistado o coração, / Cede lugar ao outro e se dá por vencido" (MOLIÈRE, 2014, p. 69). Na cena seguinte, surge Arsinóe com a intenção de contar a Célimène o que escuta sobre sua reputação, as duas iniciam uma discussão. O momento seguinte mostra Alceste e Arsinóe tecendo um diálogo que resulta em uma promessa; Arsinóe pretende entregar uma prova a Alceste que aponta a traição de Célimène.

O quarto ato, formado por quatro cenas, inicia com Éliante e Philinte conversando sobre o julgamento de Alceste. Na cena 
seguinte, Alceste acusa Célimène de traí-lo, mostrando a carta endereçada a Oronte, que lhe foi entregue por Arsinóe. Achando que foi traído, Alceste pede a mão de Éliante. No entanto, no fim, acaba por declarar seu amor a Célimène. Na última cena, aparece Du Bois, criado de Alceste, que relata a seu patrão fatos relacionados ao processo.

No quinto e último ato, sabemos que Alceste perde o processo e afirma: "A justiça me apoia e eu perco o processo!" (MOLIÈRE, 2014, p. 104). Na cena seguinte, aparecem os dois marqueses; um deles, Acaste, mostra a carta que revela o que Célimène pensava de todos os que a cortejavam, apresentando uma opinião negativa sobre eles. Alceste a perdoa e a convida à reclusão. No entanto, ela não aceita: “A solidão assusta vinte anos feitos" (MOLIÈRE, 2014, p. 121). Alceste, então, decide se isolar: "buscar pela terra um cantinho isolado,/onde há liberdade pr'um homem honrado" (MOLIÈRE, 2014, p. 122).

Vale ressaltar que $O$ Misantropo é composto por 1808 versos. Molière concede importância especialmente aos alexandrinos e seus versos refletem um trabalho dedicado ao ritmo e à musicalidade. A tradutora Bárbara Heliodora, renomada por suas traduções de William Shakespeare, empenhou-se em não deixar de lado a cadência poética do autor. Isso porque, mas do que a estrutura, o ritmo reforça os sentimentos dos personagens, os seus excessos, bem como a intensidade de suas personalidades. Alceste, por exemplo, apresenta-se sempre com alguma exaltação.

É preciso levar em consideração a complexidade que é a tradução de uma peça teatral francesa do século XVII para a língua portuguesa, dado que muitas palavras se modificam com o decorrer do tempo e com as transformações sociais. Temos que atentar também para a relevância da oralidade, já que se trata de um texto escrito para ser encenado. 
O ritmo é um aspecto que merece destaque nas discussões no campo de tradução literária. Henri Meschonnic, por exemplo, produziu uma série de estudos que se debruçam sobre essa questão. Segundo Meschonnic, o ritmo é necessário para o modo de significação, sendo um fator que não se restringe à poesia, mas que está presente em qualquer texto devendo, por isso, ser considerado no processo de tradução, bem como a oralidade e a prosódia. Meschonnic discorre a respeito no texto "Fragments d'une critique du rythme":

O ritmo é um universal antropológico: "Socialmente e individualmente, o homem é um animal rítmico.." Tanto quanto por psicanalistas, ele é definido pelos etnólogos associado ao prazer "a alegria pela alegria" " (ibid., p. 86). (...) $\mathrm{O}$ ritmo coloca o leitor no acordo. O ritmo, com ele no verbal e infra verbal, excede a apreensão linguística , e requer, além da psicanálise , a teoria histórica e comparativa da linguagem poética. O ritmo é um universal poético. (MESCHONNIC, 1974, p. 8)

Comecemos, pois, a análise das escolhas feitas por Bárbara Heliodora. Para isso, faremos uma comparação com a edição datada de 1682 . Iniciaremos com a primeira cena, do primeiro ato, onde é apresentado um diálogo entre Alceste e seu amigo Philinte. Na ocasião, Alceste condena a conduta gentil de Philinte para com todos que o cercam. No texto em francês temos o seguinte diálogo:

\section{PHILINTE}

Lorsqu'un homme vous vient embrasser avec joie, Il faut bien le payer de la même monnoie, Répondre, comme on peut, à ses empressements, 40 Et rendre offre pour offre, et serments pour serments. 


\section{ALCESTE}

Non, je ne puis souffrir cette lâche méthode

Qu'affectent la plupart de vos gens à la mode;

(MOLIÈRE, 1682, p. 2).

Bárbara Heliodora, na edição de 2014, publicada pela editora Zahar, traduz da seguinte forma essa passagem:

\section{PHILINTE:}

Se alguém chega e me abraça, com imensa alegria,

É meu dever tratá-lo com igual cortesia,

E responder às suas amabilidades,

40 Trocar civilidades por civilidades.

\section{ALCESTE:}

Eu não posso admitir conduta tão leniente,

Que a moda de hoje em dia obriga a toda a gente; (MOLIÈRE, 2014, p.15).

Verificamos que a linguagem utilizada na época de Molière, colaborava com o efeito rítmico nas frases. A palavra "joie", no século XVII, por exemplo, pronunciava-se “joué" - [ [wa], que rimava com "monnoie". Podemos, também, problematizar a ortografia, já que "monnoie" equivale ao atual "monnaie", traduzido para o português como "moeda". Bárbara Heliodora traduziu da seguinte forma a frase: "É meu dever tratá-lo com igual cortesia", ou seja, não houve uma tradução palavra por palavra; levou-se em consideração o discurso completo, tendo em vista as modificações temporais da língua; trata-se de uma escolha eficiente, pois transpôs tanto o sentido como o ritmo.

Vejamos o segundo exemplo da leitura comparada entre as versões analisadas, uma em francês, outra em português. Neste episódio, Alceste fala a Philinte sobre seu comportamento. O protagonista protesta contra a hipocrisia, as bajulações e a educação por conveniência; são 
esses os fatores que o levam a querer afastar-se do ser humano, reforçando, mais uma vez, o sentido do titulo adotado por Molière:

\section{ALCESTE}

Je ne me moque point, Et je vais n'épargner personne sur ce point.

Mes yeux sont trop blessés ; et la cour, et la ville, 90 Ne m'offrent rien qu'objets à m'échauffer la bile :

J'entre en une humeur noire, en un chagrin profond,

Quand je vois vivre entre eux, les hommes comme ils font ; Je ne trouve, partout, que lâche flatterie,

Qu'injustice, intérêt, trahison, fourberie ;

95 Je n'y puis plus tenir, j'enrage, et mon dessein

Est de rompre en visière à tout le genre humain. (MOLIÈRE, 1682, p.4).

Bárbara Heliodora traduziu a fala de Alceste da seguinte forma:

\section{ALCESTE}

Eu não brinco jamais,

E não posso poupar ninguém em casos tais, Isso fere os meus olhos, e a corte e a cidade 90 Ferem-me o fígado com bile em quantidade:

Eu fico com o humor negro, e com rancor profundo Vendo um homem correto viver num tal mundo. Só encontro, em toda parte, vil bajulação, Injustiça, mentira, calúnia e traição; $95 \mathrm{Eu}$ não aguento mais, desespero, e meu plano É cortar relações com o gênero humano. (MOLIÈRE, 2014, p. 18).

Percebe-se o propósito de deixar o texto traduzido o mais próximo possível do texto de partida. Principalmente quanto à estrutura, observamos que a contagem dos versos continua a mesma, assim como o posicionamento das rimas. A tradução mostra seguir um 
jogo rítmico. Na peça, em francês, temos nos finais dos versos: "point", "point", "ville", "bile" (...), a tradução acompanha com "jamais", "tais", "cidade", "quantidade" (...), todavia algumas mudanças quanto à ordem dos vocábulos foram necessárias para que a rima se efetivasse. Diferente da versão francesa, a palavra "bile”, por exemplo, não ficou no final da sentença.

Outra escolha marcante encontra-se no último verso, no qual ela traduz a frase: "Est de rompre en visière à tout le genre humain" como "É cortar relações com o gênero humano". Segundo o dicionário Littré, a expressão "Rompre en visière", significa romper a viseira de um adversário o que, figurativamente, pode referir-se a contradizer alguém frente a frente, ou atacar. A tradutora optou por "cortar relações"; essa escolha aproxima Molière do leitor brasileiro, tornando o sentido do texto mais claro e acessível.

Na cena dois, ainda do primeiro ato, podemos constatar uma singularidade que aponta novamente para as escolhas feitas na tradução. A fala de Alceste se situa no momento da divergência de opiniões entre Oronte e o protagonista. Nesse episódio, Alceste diz a Oronte sua opinião a respeito do soneto, isso porque Oronte, momentos antes, havia pedido seu parecer. Alceste, sem filtro, despreza os versos do admirador de Célimène. Sua repulsa é expressa no texto de partida da seguinte maneira:

\author{
ALCESTE \\ Franchement, il est bon à mettre au cabinet ; \\ Vous vous êtes réglé sur de méchants modèles, \\ Et vos expressions ne sont point naturelles. \\ Qu'est-ce que nous berce un temps, notre ennui, \\ 380 Et que rien ne marche après lui ? \\ Que ne vous pas mettre en dépense, \\ Pour ne me donner que l'espoir? \\ Et que Philis, on désespère, \\ Alors qu'on espère toujours?
}


385 Ce style figuré, dont on fait vanité,

Sort du bon caractère, et de la vérité ;

Ce n'est que jeu de mots, qu'affectation pure,

Et ce n'est point ainsi, que parle la nature.

Le méchant goût du siècle, en cela, me fait peur,

390 Nos pères, tous grossiers, l'avaient beaucoup meilleur ;

Et je prise bien moins, tout ce que l'on admire

(MOLIÈRE, 1682 p.16).

As escolhas sintáticas, semânticas e estruturais são apresentadas da seguinte maneira por Bárbara Heliodora:
ALCESTE
Na verdade, deve jogá-lo na privada.
Tomou por modelo, senhor, horrores tais,
Que as suas expressões não soam naturais
Que é nosso tédio ela embala
380 Ou nada vem para apoiá-la?
Que mas Philis só enrola
Se é precisa eterna espera,
Para o triunfo do meu zelo
A mim só resta morrer?
385 Esse estilo figurado que hoje é vaidade,
Falseia tanto o caráter quanto a verdade:
É só jogo de palavras e afetação,
E nunca fala assim a natureza, não.
Me assustam maus gostos dos versos dos senhores,
390 E nossos pais, mais rudes, faziam melhores.
E eu prezo bem menos seu modo de fazer
(MOLIÈRE, 2014, p. 36).

Mantendo a mesma quantidade de versos e um modelo semelhante de composição das rimas, responsáveis pela musicalidade, exemplificaremos outro caso particular na tradução. Especificamente o primeiro verso, de número 376. Nele, Alceste fala, na língua de 
Molière: «Franchement, il est bon à mettre au cabinet », que recebe a tradução: "Na verdade, deve jogá-lo na privada"; essa afirmação refere-se ao soneto escrito por Oronte, Alceste já enervado com a situação sugere que o soneto seja colocado no "cabinet". Essa palavra francesa pode significar um móvel antigo composto por diversas gavetas. A versão francesa, que estamos usando para a presente resenha, contém notas explicativas que auxiliam na compreensão da linguagem do século XVII. Uma dessas notas frisa exatamente a expressão « cabinet », explicando que:

Alceste veut-il dire que ce sonnet doit être oublié au fond d'un tiroir, ou fait-il allusion, comme le suggèrent les dictionnaires de Richelet en 1679 et Furetière en 1690. Le Furetière précise même: «lieu secret où on va aux nécessités de nature. Ainsi Molière a dit dans Le Misanthrope en parlant d'un méchant sonnet, «Franchement, il n'est bon qu'à mettre au cabinet.

Percebemos que a escolha da tradutora pode ter sido baseada em alguma edição francesa comentada, haja vista a escolha de usar "deve jogá-lo na privada", o que atribui um tom cômico à irritação de Alceste, ocasionando uma empatia mais imediata do público. Contudo, podemos afirmar que a tradução elaborada por Bárbara Heliodora é digna de mérito, pois além da importância semântica, é perceptível que a tradutora levou em consideração todo o trabalho rítmico proposto inicialmente por Molière. De fato, para que uma cadência fosse seguida, alguns recursos foram utilizados, como a mudança da ordem de palavras, em algumas frases, ou a supressão de letras, como na fala de Arsinoé, apresentada como amiga de Célimène:
ARSINÓE
1125 'Stá bem ; é como diz ! E sobre o assunto dado
O que vai receber 'stá bem iluminado.
(MOLIÈRE, 2014, p.121) 
Importante ressaltar que "Stá" assemelha-se ao português lusitano, comum na poesia brasileira, a exemplo de Castro Alves, no famoso poema "Navio Negreiro" que, para a composição do verso decassílabo, apresentava a supressão da vogal, como no verso: “Stamos em pleno mar... Doudo no espaço" (ALVES, 1869, p.1) Molière, em sua peça, expõe os vícios da aristocracia parisiense, desvendando, por meio de ações fictícias, como se davam as relações sociais na segunda metade do século XVII. Nela temos exemplos específicos que se desdobram em aspectos universais, representados nas figuras de Alceste, um crítico feroz da falsidade; dos marqueses, representantes da nobreza; e de Philinte, que, com sua amabilidade, mantinha bons relacionamentos. Molière pinta situações, muitas vezes de forma exagerada, atribuindo um teor cômico ao ridículo das situações. No entanto, a superficialidade e a hipocrisia dos contemporâneos de Molière são retratadas de forma intensa.

A tradução de Bárbara Heliodora moderniza e aproxima os leitores de um clássico do mundo teatral. A edição conta ainda com uma apresentação da tradutora, intitulada "Molière e a comédia de caráter", na qual afirma:

O misantropo, quando critica seu protagonista, está, ao mesmo tempo, denunciando maus hábitos da corte e da alta burguesia do tempo de Luís XIV. Até a integridade em excesso pode merecer o riso crítico da comédia, mas os vícios continuam merecendo condenação (HELIODORA, 2014, p. 10).

Além de ser uma comédia de caráter, $O$ misantropo é também uma comédia de costumes, por expor, mesmo que como pano de fundo, os hábitos sociais em um determinado contexto. A edição traz ainda a "Cronologia: vida e obra de Molière". A edição não inclui notas explicativas, que poderiam enriquecer ainda mais a compre- 
ensão dos leitores. No entanto, como se trata de um clássico, não faltará material atualizado para aqueles que desejam aprofundar-se no estudo da obra.

A ilustração de $O$ misantropo esteve a cargo de Rafael Nobre Babilonia Cultural Editorial. Visualmente trata-se de um livro de porte pequeno, em brochura, o que facilita, por exemplo, ser utilizado durante as leituras de ensaios teatrais, já que é perceptível a oralidade na peça de Molière, oralidade que é inerente ao teatro, já que se trata de um instrumento para aproximar o texto do público.

Recebido em: 09/04/2017

Aceito em: 21/06/2017

Publicado em setembro de 2017 